\title{
Reseña de: Di Tullio Arias, Anabella. Teoría feminista y libe- ralismo. El devenir de una relación problemática. Universidad de Málaga, 2016
}

\author{
Isabel G. GAMERO \\ Universidad Nacional de La Plata - CONICET
}

\section{TEORÍA FEMINISTA Y LIBERALISMO, UNA RELACIÓN COMPLEJA}

«Feminismo»y «liberalismo» se dicen de muchas maneras, pero, en todas ellas, su relación es problemática, como sostiene Anabella Di Tullio en el subtítulo de su libro Teoría feminista y liberalismo (XXVI Premio Victoria Kent).

En este libro la autora trata de dirimir esas complejas relaciones, con el objetivo de matizar la visión dominante del feminismo que asegura ser incompatible con el liberalismo. Para ello, en los primeros capítulos, reconstruye y aclara las teorías de las principales autoras que se entienden como feministas y liberales: Jean Hampton, Martha Nussbaum y Susan Moller Okin. Mediante la exposición de estas propuestas, Di Tullio argumenta que muchas críticas feministas en oposición al liberalismo (por ejemplo, por su estricta separación entre lo público y lo privado y su comprensión formal y neutra de la justicia) pueden resultar adecuadas para objetar propuestas como la de Rawls. No obstante, estas críticas no resultan tan certeras cuando se profundiza en la obra de estas tres autoras, quienes fueron muy críticas con la propuesta rawlsiana y lograron transformar y ampliar el liberalismo para hacerlo más feminista y más consistente con los propios principios liberales.

Sin embargo, Di Tullio no se limita a hacer una descripción teórica e histórica de estas propuestas, ni acepta sin ambages su feminismo liberal, sino que las «pone a prueba», esto es, traslada estas teorías a temas y polémicas actuales, como el aborto (135), las injusticias o desigualdades que se dan en el ámbito privado o familiar (125 y ss.), la subordinación o instrumentalización de las mujeres en muchas esferas (153 y ss.) y las dificultades ligadas al consentimiento y la libre elección, con especial atención a los casos en los que una mujer decide sacrificarse y anteponer los intereses de otras personas 
a los suyos propios (165 y ss.). Di Tullio reconstruye las respuestas que estas autoras han dado (o podrían dar) sobre estas cuestiones y da así una imagen más completa y adecuada del liberalismo feminista, para mantener que (al menos según estas tres autoras) estas dos corrientes no sólo son compatibles sino que se refuerzan entre sí. Es decir, por un lado, la concepción liberal de un sujeto autónomo puede servir para empoderar a las mujeres y el concepto de justicia liberal se puede trasladar a otros ámbitos (como la esfera privada y familiar) para apoyar la lucha feminista. Por otro lado, la crítica feminista puede dar lugar a un liberalismo sin sesgos patriarcales y más atento a otros ámbitos, desatendidos por los autores liberales varones, como la vida familiar y los cuidados; así como a un liberalismo preocupado por las diferencias culturales, que intenta no imponer sus conceptos occidentales sobre otras formas de vida, sino entender las diferencias y crear luchas comunes. Ahora bien, éste ya no es el liberalismo clásico de los libros de texto y que teorizó Rawls sino que, al vincularse con el feminismo, emerge un nuevo liberalismo, no jerárquico y basado en la igualdad, real y material, de oportunidades que Di Tullio denomina «liberalismo in between» (siguiendo un término de Okin, 128), «ilustrado» (expresión de Hampton, 128), «radical» (202), «parcial» (135) o «híbrido» (196 y 203).

A modo de ejemplo de esta transformación o hibridez, se propone la crítica social feminista de Brooke Ackerly, quien hace una revisión crítica de la obra de Nussbaum y traslada el enfoque de las capacidades a los procesos de toma de decisiones en distintas culturas, con el objetivo de que todas las opiniones se puedan expresar y se promueva el empoderamiento de las mujeres. De este modo, Di Tullio muestra que las teorías o corrientes de pensamiento no son tan simples y claras como se describe en los manuales de filosofía, sino que resulta necesario situarlas, contextualizarlas y ponerlas en práctica para comprobar si funcionan y superar así el debate teórico abstracto.

Ahora bien, no todo van a ser halagos al liberalismo. En la segunda parte del libro, y siguiendo las obras de Carole Pateman, Catharine MacKinnon y Virginia Held, Di Tullio desarrolla otras críticas, menos superficiales y más radicales y certeras, que se han dirigido desde el feminismo al liberalismo. También en este caso, la autora no se limita a exponer estas propuestas teóricas, sino que las problematiza y pone a prueba, trasladándolas a polémicas y preocupaciones actuales. Esto lo hace a través de distintos dilemas que constituyen la argumentación más elaborada, fértil y compleja del libro, ya que las fuentes teóricas se multiplican tanto como la amplitud de temas y enfoques. Por ejemplo, Di Tullio plantea los límites del feminismo cuando oscila entre la igualdad y la diferencia (365 y ss.) y vuelve a traer a colación las polémicas 
sobre la libre decisión de las mujeres, el consentimiento y la sumisión (394 y ss.). También destaca dilemas clásicos de la teoría política, como los de igualdad versus libertad y libertad versus necesidad (398 y ss.) o el que enfrenta derechos universales a derechos particulares de grupos y colectivos (397 y ss.). Asimismo, tiene en cuenta dilemas de la filosofía contemporánea, como el que pregunta si hay identidades fijas o esenciales (como «la mujer») o si somos identidades construidas, posmodernas y cambiantes ( 378 y ss.), en el enfrentamiento entre la «fiebre deconstructiva que intenta eliminar el sujeto» y la «multiplurimanía» que multiplica las diferencias culturales y las aísla en culturas cerradas (383).

Llevando estas tensiones y dilemas hasta sus límites, Di Tullio muestra algunas debilidades del liberalismo feminista y, al mismo tiempo, dirige objeciones a las autoras que son críticas con esta corriente. Elabora así una metacrítica, o crítica dentro de la crítica, para aclarar el panorama, tan complejo, de la teoría feminista contemporánea y sus contiendas, y mostrar, de nuevo, que no todo es tan sencillo y delimitable en claras categorías teóricas sino que, por el contrario, las teorías afectan a las vidas y las experiencias vividas impactan en la forma de teorizar, considerando que toda teoría y práctica feminista debe tener en cuenta esta interconexión (421).

Para cerrar la argumentación y dar alternativas, en las consideraciones finales del libro Di Tullio se posiciona con su propia voz, y aporta una lúcida reflexión sobre la libertad y sobre cómo lograr una concepción más adecuada de lo que significa ser humano y de cómo nos relacionamos con los demás, no sólo en un plano teórico sino también en nuestras vidas.

A pesar de la amplitud de temas y enfoques, la lectura del libro es sencilla y amena, ya que la autora no se aparta de su tema de interés (las relaciones entre feminismo y liberalismo) e hila los argumentos con soltura y fluidez, relacionándolos con temas cercanos y actuales. En definitiva, Teoría feminista y liberalismo es un libro altamente recomendable, no sólo para enseñantes y estudiantes de filosofía y feminismo, sino también para activistas, personas interesadas en teoría política contemporánea y para quien desee conocer en profundidad y con justeza las distintas manifestaciones del liberalismo. También puede resultar de gran utilidad para eliminar prejuicios debidos a la comprensión superficial de esta corriente, y poder criticarla de modo más adecuado y certero (al menos quien escribe esta reseña ha logrado superar algunos de sus prejuicios sobre el liberalismo, ahora entiende mejor esta forma de pensar y, aunque sigue sin estar de acuerdo con ella, en el libro ha encontrado mejores argumentos para reforzar sus críticas). Asimismo, en la necesaria imbricación entre lo público y lo privado que se destaca en todo momento 
en el libro, se proponen contenidos y direcciones para debatir y reflexionar sobre otras preocupaciones, acuciantes aunque poco frecuentes en la filosofía, como los cuidados y la maternidad. Por último, todo el libro es un argumento contundente (de cuatrocientas páginas y un centenar de fuentes teóricas) para refutar a quien todavía ose mantener que no hay mujeres pensadoras o filósofas.

Para finalizar, resulta destacable, consecuente con el planteamiento crítico del libro y muy de agradecer que Anabella Di Tullio haya decidido utilizar el plural inclusivo para escribir su texto. Este recurso le sirve para ilustrar que, tanto en el lenguaje como en los conceptos liberales, el plural genérico masculino parecía ser neutro y universal, referirse a toda la humanidad, cuando en realidad se trataba de un uso particular y de una concepción sesgada del mundo que surgió en un ámbito occidental y eminentemente masculino. Argumenta de este modo la autora que ni este uso genérico ni esta concepción formal y liberal se van a transformar, simple y automáticamente, porque las mujeres comiencen a seguirlos, sino que es necesario un análisis más profundo y crítico (como el que presenta este libro), así como un cambio en las prácticas, en las creencias y en las actitudes. De este modo, el lenguaje, los argumentos, las prácticas y las críticas se entrelazan en el texto de Di Tullio para promover una verdadera igualdad entre hombres y mujeres, no la pretendida igualdad formal que propugnaba el liberalismo, anterior al feminismo. 